\title{
Legitimidade de Instituições de Governança Global ${ }^{1}$
}

\author{
Legitimacy of Global Governance Institutions
}

Mariana Mattos de Almeida Cruz²

\section{RESUMO}

O objetivo principal é discutir o debate nas Relações Internacionais sobre o conceito de legitimidade das instituições internacionais a partir da perspectiva do neoinstitucionalismo. Pretende-se também discutir a legitimidade do Conselho de Segurança como um órgão da Organização das Nações Unidas.

Palavra-chave: Legitimidade; Instituições; Conselho de Segurança.

\begin{abstract}
The main goal is to discuss the debate about the legitimacy of global governance institutions in International Relations trough the theory of neoinstitucionalism. We also aim to discuss the UN Security Council's legitimacy as an international organization.
\end{abstract}

Key-words: Legitimacy; Institutions; Security Council.

Mesmo que o termo legitimidade seja de freqüente uso no estudo de instituições internacionais, pouca atenção tem sido dada à significação ou funcionamento de tal conceito Hurd (2007). O tema, apesar de atual na agenda de pesquisas de Segurança Internacional, e presente em diversas elaborações teóricas do campo, não apresenta uma sistematização ou explicações causais de seu funcionamento. "There is no available model of legitimacy for use in international relations that would allow serious inquiry into its causes, consequences, and implications." (HURD, 2007, p.2)

Em se tratando de teoria, realistas e liberais com freqüência associam a utilização do argumento da legitimidade como uma tentativa de defender seus interesses contra ameaças ou seus oponentes. Stephen Krasner (1993) descobre que na história de Westphalia a ideia de soberania foi usada para legitimar o direito do soberano de

\footnotetext{
${ }^{1}$ Artigo recebido em 30 de agosto de 2013 e aprovado para publicação em 13 de setembro de 2013.

2 Mestranda do Programa de Pós Graduação em Ciência Política da Universidade Federal do Paraná e pesquisadora do Núcleo de Pesquisa em Relações Internacionais (NEPRI/UFPR), Curitiba, Brasil.
} 
recolher taxas e de reforçar a posição do Estado, enquanto Goldstein e Keohane (1993) discutiram de uma forma mais geral que atores com mais poder usam ideias para legitimar seus interesses. E, dentre as correntes interpretativas de Relações Internacionais, a legitimidade é frequentemente relacionada a existência de uma sociedade internacional Bull (1995). A sistematização teórica nos estudos de RI revela uma identificação da questão da legitimidade, mas uma definição ou análise sobre seus mecanismos de funcionamento ainda não podem ser interpretadas.

Em uma análise mais recente, Buchanan e Keohane, em The Legitimacy of Global Governance Institutions (2006), comentam que o debate sobre a legitimidade num contexto de instituições de governança global comumente deixa de ser claro pois faltam algumas distinções conceituais essenciais. Para os autores, a distinção entre legitimidade e justiça é essencial: "We argue that legitimacy assessments are not reducible to claims about self-interest, show that justice and legitimacy ought to be kept distinct, and identify the conception of legitimacy that is central for global governance institutions" (BUCHANAN \& KEOHANE, 2006, p.1).

Keohane (2011) comenta que como as instituições de governança global fazem parte de um fenômeno que está sujeito a mudanças constantes é difícil criar um conceito atemporal do que legitimidade significa. 0 máximo que se pode fazer é uma proposta de como essa legitimidade é avaliada no momento presente.

Assim, em seu artigo, Buchanan \& Keohane (2006) fazem uma proposta de um conceito de legitimidade que corresponda a uma série de critérios, aos quais instituições de governança global deveriam corresponder para serem consideradas legítimas, o que os autores chamam de "padrão complexo". Esse padrão identifica a necessidade de um canal de accountability que seja possível pelo consentimento de estados democráticos; três critérios essenciais (aceitabilidade moral mínima, benefícios comparativos e integridade institucional; e medidas epistêmicas eficientes para lidar com a incerteza factual e normativa (BUCHANAN \& KEOHANE, 2006).

Outro elemento essencial na legitimidade de instituições internacionais reside nas relações entre tais instituições e seu contexto sócio-político: "in particular, external agents, which monitor and criticize the operation of international institutions, are crucial to their ongoing legitimacy. Respect for democratic values is essential for 
legitimacy, but this does not imply that procedures analogous to domestic democratic procedures are necessary at the global level" (BUCHANAN \& KEOHANE, 2006, p.1).

Em The Morality of Freedom, Raz "nega a existência de uma obrigação geral de obedecer a lei mesmo numa sociedade razoavelmente justa" (Raz, 1986, p.70). Isto significa que legitimidade não é para o autor uma qualidade binária que autoridades ou a possuem ou falta-lhes completamente. Para ele, a legitimidade é fragmentária por sua natureza (1986).

Para Raz (1986), a questão de legitimidade é intrinsecamente relacionada com a questão da autoridade, tendo como questão central a obediência. Assim, a obediência é legítima se pode ser justificada. Para tanto, as razões para a obediência são válidas na medida em que são razões para ação. 0 critério de validade da norma deve ser diretiva, "autoritativa", ou seja, há a necessidade de autoridade para estabelecer ordem e diretivas para os indivíduos. Estas razões são independentes do conteúdo, não havendo relação direta entre razão e ação (RAZ, 1986).

Assim, com papel central em seu conceito de autoridade está a relação entre um indivíduo e o Estado, relação esta mediada pelas norma legal ou uma série de normas legais. Consequentemente, para o autor: "[i]t is not good enough to say that an authoritative measure is justified because it serves the public interest. If it is binding on individuals it has to be justified by considerations which bind them." (Raz, 1986, p.72) Para embasar o conteúdo desta declaração, Raz introduz a tese dependente e a tese de justificação normal. Juntas, essas teses captam o conceito normativo de autoridade moralmente justificável.

Para Hurd (2007), a legitimidade pode ser definida como a crença normativa de um ator de que uma regra ou instituição deve ser obedecida. Assim, uma instituição que exerce poder legítimo está em posição de autoridade Hurd (2007). Segundo o autor, se uma organização internacional é legítima, ela pode ser interpretada como possuidora de autoridade soberana. Soberania, aqui entendida como o "direito de exercer autoridade final" sobre um povo e território, está distribuída entre diversos atores no sistema internacional, como Estados e instituições internacionais como o Conselho de Segurança das Nações Unidas, que, segundo Hurd (2007), exerce poder legítimo sobre os Estados. A presença de autoridades soberanas em atores não estatais sugere, segundo o autor, que 
o termo anarquia internacional não está mais correspondendo à realidade do sistema internacional. "The international system comprises diverse actors with legitimated power and so has diverse locations of sovereign authority. State interactions occur in a social space that contains authoritative institutions like the Council, and this contradicts the "anarchic" premise of much contemporary IR scholarship" (HURD, 2007, p.3).

Assim, o principal objeto deste estudo de Hurd (2007), o Conselho de Segurança das Nações Unidas é considerado potencialmente como a mais poderosa organização internacional do sistema internacional, o que o torna um elemento essencial para uma análise empírica sobre a operação da legitimidade no sistema internacional: "its peculiar combination of extensive powers and political limitations means that its effectiveness depends on its legitimation" (Hurd, 2007, p.12).

Lopes e Casaroes (2009) lançaram uma reflexão sobre a correlação entre a autoridade política detida pelas Nações Unidas e sua capacidade efetiva de coerção, conceitos que se relacionam com a legitimidade da instituição. A partir de sua reflexão, os autores concluíram que não há uma tensão real entre as duas variáveis, ou seja, a autoridade política da ONU não se relaciona diretamente com sua capacidade de coerção - já que ela se difere em diversos aspectos de um Estado, e não é dotada de força legítima (LOPES \& CASAROES, 2009).

0 artigo elenca alguns elementos que fundaram e reiteraram tal autoridade política: a pretensão de universalidade, a pretensão de imparcialidade, a vantagem cognitiva comparativa em certas áreas temáticas e a formação institucional inclusiva e, naturalmente, o processo de aceitação de tais elementos pelos Estados-membros, são características que conferem à ONU um significativo grau de autoridade política (LOPES \& CASAROES, 2009).

Hurd (2007) realiza, portanto, uma análise histórica do Conselho de Segurança. O autor o considera uma fonte observável de legitimidade, pois sua ostensividade é causada majoritariamente pela disposição da maior potência material que qualquer organização internacional na história, e mesmo assim a instituição tem grande dificuldade para dispor deste poder.

Desta feita, para Hurd (2007), a legitimidade é relevante para instituições 
formais, informais ou internacionais, e também para o sistema internacional como um todo. Esta conclusão reside no fato de que a legitimidade, portanto, afeta a decisão de cálculo de atores com relação à obediência; ela empodera os símbolos da instituição, que pode se tornar também fonte de recursos políticos e que pode ser apropriada por atores para seus próprios propósitos; e é o elemento central para se reconhecer atores como autoritários. "The possibility of international authority in international organizations (as opposed to that authority in the traditional form of the nation-state that we are accustomed to) creates a problem for theories of IR that start with the premise of "anarchy." (HURD, 1999 p.404)

\section{Referências Bibliográficas}

BUCHANAN, Allen; KEOHANE, Robert Owen. The Legitimacy of Global Governance Institutions. Mimeo. 2006

HURD, Ian. After Anarchy: Legitimacy and Power in the United Nations Security Council. Princeton: Princeton University Press, 2007.

HURD, Ian. Legitimacy and Authority in International Politics. International Organization. Vol. 53 n. 2, (Spring, 1999), p.379-408.

JERVIS, Robert. "Realism, Neoliberalism and Cooperation: Understanding the debate". International Security. Vol. 24, nํㅜ, summer 1999. pp. 42-63.

KEOHANE, Robert Owen. Global Governance and Legitimacy. Reviwe of International Political Economy 18:1, 99-109, 2011.

KEOHANE, Robert Owen. "International Institutions: two approaches." International Studies Quartely. Vol. 32, n.4, pp. 379-396, 1998.

KEOHANE, Robert Owen. After Hegemony: cooperation and discord in the world political economy. Princeton: Princeton University Press, 1984.

LOPES, Dawisson Belém; CASAROES, Guilherme Stolle Paixão e. ONU e segurança coletiva no século XXI: tensões entre autoridade política e exercício efetivo da coerção. Contexto Internacional, Rio de Janeiro, v. 31, n. 1, Apr. 2009.

RAZ, Joseph. The Morality of Freedom. Oxford: Oxford University Press, 1986. 